\title{
TO DANCE OR NOT TO DANCE: MASCULINITIES IN AKAN PROVERBS AND THEIR IMPLICATIONS FOR CONTEMPORARY SOCIETIES
}

\author{
Grace Diabah and Nana Aba Appiah Amfo
}

\begin{abstract}
This paper looks at how men are represented in Akan proverbs and the implications of such representations for contemporary Ghanaian men. It assesses the traditional views on what it means to be 'a man' among the Akan and how Ghanaian men perceive these in contemporary times. This is particularly relevant in an age when the demands of the modern world (high living standards, economic hardships, high unemployment rates etc.) put undue pressure on both men and women. More so, it is an age when women are increasingly being empowered to take up traditionally masculine roles. Such an enterprise aligns with the call on feminist and gender researchers to consider studying how men experience and enact gender. Thus, we explore the dilemmas of the contemporary Ghanaian man as he negotiates the expectations of traditional Ghanaian societies and the demands of contemporary families. We analyse 44 Akan proverbs on men, collected from texts and oral sources, as well as responses from focus group discussions on these proverbs. The results show that men are expected to be brave, providers, protectors, and action or results-oriented. Men who are unable to live up to expectation are considered not men enough; they are often perceived as women's puppets. Reponses from our focus group discussions suggest that such representations put undue pressure on men to fulfil societal expectations; and as research has shown (for example, Ratele 2008), failure to fulfil such expectations can find expression in violence.
\end{abstract}

Keywords: Akan/Ghana, Africa, contemporary societies, masculinities, men, proverbs, 


\section{Introduction}

This paper is an exploration of concepts of masculinities in traditional Akan societies as espoused in their proverbs. It forms the basis for extrapolating on the concepts of masculinities in the Ghanaian society, considering the pervasiveness of the Akan language and culture in the Ghanaian society (see section 3). Further to that, it examines the sustenance of such concepts in the contemporary Ghanaian society. The paper is a follow-up to Diabah and Amfo (2015), where we consider traditional views on the perceptions and roles of women in Akan societies/Ghanaian society as represented in Akan proverbs. We find it appropriate therefore to examine what Akan proverbs have to say about the expectations of the role of men in its society. Such an enterprise aligns with the call on feminist and gender researchers to consider studying how men experience and enact gender, the relationship between individual males and groups of males, and between males and females (Lindsay and Miescher 2003, Adomako Ampofo 2011). We share Kiyimba's (2010) assertion that the concept of male/masculinity in African oral literature (including proverbs) has not been adequately explored.

The paper therefore examines the representation of men as reflected in a number of Akan proverbs. The aim is to analyze traditional views on what it means to be a man - what one looks like, his social roles, expected behaviour etc. - in the Akan society (and by extension, the Ghanaian society) and explore the interrelation between language, gender and culture. We also explore, through focus group discussions, the implications of these traditional views on masculinities from men in contemporary Akan/Ghanaian society. The analysis is done within the context of African or Ghanaian masculinities (Miescher 2005, Uchendu 2009, Adomako Ampofo and Boateng 2011, Fiaveh, Izugbara, Okyerefo, Reysoo and Fayorsey 2015) and hegemonic and nonhegemonic masculinities (Connell 2005, Schippers 2007). We examine the masculinities represented by these proverbs in the light of traditional and contemporary gender relations within the Ghanaian society.

The rest of this paper is organized as follows. Section 2 provides a description of the proverb and its role in the African society. In section 3, we present a sociolinguistic overview of our study context, following which various concepts of masculinities, which forms the basis for our discussion are presented in section 4 . In section 5, the data and methods for the study are provided. The discussion of the data based on the identified categories is done in section 6 . Section 7 briefly considers how traditional views are faring within contemporary contexts. Section 8 is the conclusion. 


\section{Proverbs}

Proverbs are often considered to represent the collective wisdom of societies which use them. It is deemed that proverbs exist across all cultures and societies, they are therefore considered as a universal phenomenon, which permeates communication across societies. Durkheim (1933: 170-171) defines the proverb as "a condensed statement of a collective idea or sentiment relative to a determined category of objects". He suggests the collective nature of the proverb and further elaborates on the communal value of the proverb by asserting that "every thought tends towards an expression adequate to it, if it is common to a certain number of individuals, it necessarily ends by being enclosed in a formula that is equally common to them" (p.170-171). Our choice of proverbs as an object of study, in our attempt to decipher the Akan society's concept of masculinities, is grounded in the collective nature of the proverbs. As reflected in Durkheim's definition, proverbs by their nature do not reflect individual thoughts, but rather they are reflective of communal opinions. Asante (2002) agrees with this view when, talking about Akan proverbs, he suggests that they express certain facts of life which have been arrived at as a result of careful observation.

In highlighting the potent and illuminating nature of the proverb, Kalu (2010: 1) describes it as "that ubiquitous verbal art whose formulaic structure provides moments of clarity in the daily commerce of African life". Thus, we believe that an interrogation of certain gendered Akan proverbs will provide insights into the traditional collective view of what is considered masculine and expected of males in the Akan society and, by reasonable extension, the Ghanaian society. Indeed, exploring proverbs in the quest to understand the notions of masculinities (or gendered relations more generally) in various societies is not completely novel. A number of chapters in Mugambi and Allan's (2010) edited volume on Masculinities in African literary and cultural texts dwell on the proverb as a basis for understanding certain gendered notions. Kalu (2010: 2) sums this idea up suitably when she suggests that "[ $t$ ]he proverb is notable simultaneously for its practical wisdom, its symbolism and its insight into gender complementarity".

\section{A Socio-linguistic Overview}

The label Akan is an ethnolinguistic one, used in reference to a specific group of people found in southern Ghana who have a shared culture and a common language. The Akans (with their various sub-divisions) collectively represent $47.5 \%$ of Ghana's population (Ghana Statistical Service, 2012). Even though there are various sub-divisions of the 
larger ethnic group, the Akans are largely identified by their matrilineal custom, which forms the basis for inheritance and succession. ${ }^{1}$

The Akans originate from five out of ten regions in Ghana. ${ }^{2}$ These are the Asante, Central, Eastern, Bono Ahafo and Western regions of Ghana. However, due to migration, they can be found all over the country. This is evidenced in the popularity of their language in other parts of the country as well. It is therefore apt for Simons and Fennig (2018) to describe Akan (and English) as the principal languages in Ghana. Earlier authors such as Guerini (2008), Essegbey (2009) and Bibiebome (2010) have all attested to the dominance of the Akan language even in the indigenously Ga capital of the country - Accra. It has been estimated that in addition to almost half of the population speaking it as their mother tongue, up to two-thirds use it as a lingua franca (Obeng 2005).

Considering the dominance of the Akan language in the country, we can assume that data from Akan is largely representative of the country. Akan has eleven dialects, out of which three are often referred to as the main dialects. This is because these three dialects (Asante, Akuapem and Mfantse) have been codified and are therefore considered as the literary dialects. The data used for this study are from the Asante dialect.

\section{Men and masculinities}

Masculinity is what is traditionally associated with males. It is socially and discursively constructed, fluid, resulting in diverse forms across different contexts and mediated by various factors such as age and social status (Adomako Ampofo and Boateng 2011). Uchendu (2009) therefore defines masculinity as what a given society accepts as features associated with males and the expressions of maleness. From the cultural perspective on men and masculinities, Edley and Wetherell (1996: 105) also note that "every culture in the world must contain its own specific set of ideals or themes which relate to men and masculinity". This provides members of the community with "a shared understanding of what it means to be a man: what one looks like, how one should behave and so forth" (Edley and Wetherell 1996: 106). What may therefore be considered an ideal masculine behaviour, or otherwise, in Ghana may not necessarily be ideal in the UK, for example. In the literature on men and masculinities in Ghana, we identify certain ideals of masculinity like bravery or courage, resilience to pain, power, strength (both physical and emotional), virility, the ability to offer protection,

\footnotetext{
${ }^{1}$ The exception to this is the Akuapem sub-group, who are patrilineal.

${ }^{2}$ Akans can be found in La Cote d'Ivoire as well, for our paper, we concentrate on the Akans and their language in Ghana.
} 
capacity to amass wealth, intelligence and wisdom, assertiveness, expression of authority and leadership qualities, exhibition of breadwinning competencies, phallic competence, among others (see Amoah 1991, Obeng 2003, Miescher 2005, Adomako Ampofo and Boateng 2011, Adinkra 2012, Diabah and Amfo 2015, Fiaveh, Izugbara, Okyerefo, Reysoo and Fayorsey 2015, Adjei 2016).

Deeply entrenched in studies on men and masculinities is the notion of hegemonic masculinity, which is defined as a dominant form of masculinity in a given setting (cf. Connell 1995, 2005). Schippers (2007: 94) defines it as "the qualities defined as manly that establish and legitimate a hierarchical and complementary relationship to femininity and that, by doing so, guarantee the dominant position of men and the subordination of women"; but this domination is amenable to contestations and struggles from women (Diabah 2011, Wetherell and Edley (1999). Hegemonic masculinity also operates through the subordination or marginalization of other masculinities it coexists with. It distinguishes itself from other masculinities and establishes itself by identifying, highlighting and celebrating certain characteristics (like exhibition of power and strength, resilience to pain, bravery etc.) as the true reflection of masculinity; and note that such characteristics will be context-specific. It thereby downgrades any potential value in other kinds of masculinities. Adomako Ampofo and Boateng (2011: 42) for instance note how men who do not fit into Ghanaian cultural ideals of masculinity may be ridiculed as being "female-men" (see also Diabah 2015). The understanding being that, although they are men, biologically, they construct themselves in ways that are considered as feminine (Diabah 2015). Hegemonic masculinity therefore "provides a way of explaining the fact that, though a number of masculinities coexist, a particular version of masculinity has supremacy and greater legitimacy in society" (Adomako Ampofo and Boateng 2011: 42).

As we interrogate how men are constructed in Akan proverbs, and the implications of such constructions for men in contemporary Ghanaian society, we shall draw on these notions of hegemonic and non-hegemonic (marginalised) masculinities.

\section{Data and Methods}

This paper is based on a selection of 44 Akan proverbs that relate to men. 31 of these proverbs were extracted from Appiah et al.'s (2007) extensive collection of 7015 Akan proverbs: Bu me be: Proverbs of the Akans, and 13 from direct oral sources. Those from the oral sources were gathered from final year students of a Language and Gender class (2016 and 2017 year groups) and other native speakers of Akan. Most of these proverbs explicitly mention sbarima (or its plural form mmarima), the Akan word for male, which in many instances is aptly translated as "man/men". In some cases, a derivative 
of sbarima (such as nkokora, "old men" and mmrantec "young men") is used, or concepts and names that are intrinsically linked to the notion of male, like kunu "husband", Bckoe "warrior". The data were checked with our focus group participants and other native speakers we encountered during presentations of aspects of our work ${ }^{3}$. In some instances, we amended Appiah et al.'s English translations of the proverbs based on our understanding of the proverbs and recommendations/suggestions from our focus group participants and other native speakers.

To interrogate the implications of men's representations in these proverbs for contemporary Ghanaian men, we conducted two focus group discussions (FGDs) with some male students from the Master of Arts (MA) Teaching English as a Second Language (TESL) class. Group 1 was made up of 7 Year 1 students and group 2 was made up of 6 Year 2 students. Our FGD participants were from different ethnic backgrounds; they were either natives of Akan or fluent second language speakers of Akan. Each group had both married and unmarried men, as well as Christians and Moslems. The participants were asked to comment on the proverbs by giving their interpretations or understanding of each of them and indicate how these apply to men, generally, and to them in particular. They were also expected to comment on whether they think these proverbs have outlived their relevance in contemporary society. Responses were audio-recorded and transcribed for analysis.

To fulfil our promise of confidentiality and anonymity to participants, pseudonyms have been used. For each group, participants are assigned numbers, so a combination of these numbers and the year group will be used as pseudonyms. For example, P1Y1 refers to participant 1 in the year 1 group (the others in this group will be P2Y1, P3Y1, P4Y1, P5Y1, P6Y1, P7Y1) and P1Y2 refers to participant 1 in the year 2 group (the others will be P2Y2, P3Y2, P4Y2, P4Y2, P6Y2).

We analysed the data by looking for recurring patterns or themes in the selected proverbs. Based on our understanding of the proverbs, formed as a result of our native speaker competences and prolonged contact with the language community, the proverbs were put into 8 categories. Subsequently, each category and the meaning of each proverb were verified with our focus group participants. Interaction with our focus group participants and other native speakers who we encountered during presentations of aspects of this article, as well as our extensive reading on the literature on proverbs in Africa, resulted in a reorganisation of the categories, which we present in the following section.

\footnotetext{
${ }^{3}$ This paper was presented in these two conferences: International Symposium in honour of Professor Florence Abena Dolphyne, 28 February 2018, University of Ghana, and the $2^{\text {nd }}$ School of Languages Biennial Conference (SOLCON II), 24-26 October, 2017, University of Ghana.
} 


\section{Data Presentation and Analysis}

As noted in the previous section, the proverbs were put into 8 categories based on emerging themes. These include men and bravery (17 proverbs), men as protectors (3), men as action- or results-oriented (5), men as providers (4), men as lecherous (3), the superiority of men (6), consequences of polygamy (2) and marginalized masculinities (4).

\subsection{Men and Bravery}

Bravery is one of the major marks of masculinity among Ghanaians (and in many cultures as well). In their discussion of notions of masculinity and femininity in Ghana, Fiaveh, Izugbara, Okyerefo, Reysoo and Fayorsey (2015) note that discussions on bravery and courage (and potency) were at the core of initiation rites for boys (cf. Sarpong 1977, Opoku 1978). In the Akan language, for instance, being bold is equated with being a "man" since "the Akan expressions, ne bo ye duru or ne koko ye duru (he's brave) carry a similar meaning to syc sbarima (he's a real man)" (Fiaveh, Izugbara, Okyerefo, Reysoo and Fayorsey 2015: 651, cf. Adinkrah 2012). In contemporary society where the rites of passage from boyhood to manhood are no longer practised in many communities, parents still constantly remind their boys of the fact that being a man is being brave and courageous. It is therefore not surprising that, out of a total of 44 Akan proverbs on men used in this paper, 17 compare manliness with various acts of bravery and courage. The following examples illustrate this point further:

1. Se wokshwe Ohintinpraku asa a, wohyia wo wuo, woanko nso a, wo yere ne wo mma sere wo.

'If you go out to watch the dance of Ohintinpraku, you meet your death; if you do not go, your wife and children will ridicule you'

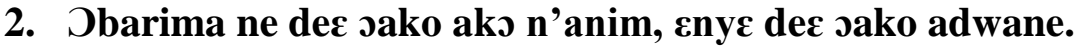

'A man is he who fights to the end, and not he who fights and runs away'

3. Bekoe din fata no a, efata no akono, ennye gyeduase.

'If Bekoe (Literally, he who comes to fight) deserves his name, he does so at the warfront and not under a shady tree (tree of reception)'

\section{Etuo to a esi sbarima bo}

'If one pulls the trigger of a gun, it lands on the chest of a man'

In example (1), the socio-cultural expectation that men should be brave is compared to going to watch the "dance" of owhintinpraku - a very deadly venture. Ohwintinpraku 
is believed to be a kind of trap used for 'big' animals like okwaduo etc. When the trap releases, it comes with so much force that it traps all kinds of things in its way (personal communication, Kofi Agyekum ${ }^{4}$ ). Going to watch an ohwintinpraku's "dance" (how it releases to catch animals) will mean putting one's life in danger, but failure to take the risk is perceived as an act of cowardice, resulting in the possibility of one being ridiculed by one's own wife and children. This proverb thus epitomizes the height of bravery, as one of the major ideals of masculinity in the Akan society. In a similar vein, example (2) suggests that what makes a man is his ability to fight (whatever storms there may be) to the end, even if it means dying in the process. Similarly, example (3) suggests that the bravery of a man is demonstrated at the war front, not in the comfort of the shade of trees. Thus, the expectation is that men should confront the difficult issues of life, rather than adopt an avoidance strategy. Participants from our focus groups largely agree that although caution should be exercised, dying in bravery is dying in honour (e.g. going to watch owhintinpraku asa, (1); fighting to the end (2); or receiving the bullets, (4)) and this is better than living a life of cowardice. P3Y2 for instance notes that "like in war ... no matter what the situation is, you continue. If you die at the warfront, you are considered as a hero". This accounts for the honour given to war heroes.

Responses from the FGDs again suggest that exhibiting such courage or bravery, especially when it concerns protecting one's family, is key to understanding who a man is in contemporary society as well. This is how P5Y2 puts it:

P5Y2: ... it is like a man facing a problem. You need to face the problem squarely, to the end. You don't have to draw back ... if you fight to the end and you lose, people will still see the efforts you have made ... if you die in the end, you are a hero!

As noted by P1Y2, boldly confronting these life's challenges on behalf of the family is also consistent with perceiving men as the shield of the family (see also section 6.2). Like in example (4), a man is one who is able to receive life's "bullets" on behalf of his family and deals with them to the end. The idea is not that a man should necessarily be engaged in physical fights. They are expected to face life's challenges. Life is a battle and men are expected to fight it boldly and fiercely to the end.

\footnotetext{
${ }^{4}$ Kofi Agyekum is a Professor of Akan Linguistics at the Department of Linguistics, University of Ghana, Legon. He specializes in Akan oral literature, pragmatics, media and political discourses.
} 


\subsection{Men as protectors}

As is typical of patriarchal societies like Ghana, men are the heads of the family and are thus expected to play dominant and leading roles. They are not only expected to wield authority (Adomako Ampofo, Okyerefo and Pervarah 2009) and provide for the material needs of their family, but they are to provide them with protection too. The relevance of this protection, particularly for women, is seen in the following proverbs:

\section{Jbaa ye turo mu nhwiren, ne kunu ye ne ho ban}

'A woman is a flower in the garden, her husband is the fence'

6. Obaa a onni barima na yebo no yi akyea

'A woman who has no male (company) is the one we beat up/assault and walk away with impudence'

\section{Jbaa to etuo a etwere barima dan mu.}

'When/if a woman buys a gun, it is kept in a man's room'

In their discussion of the representation of women in Akan proverbs, Diabah and Amfo (2015) note how women are represented as vulnerable, weak and powerless, as in example (5). Men, on the other hand are represented, through the metaphor of a fence, as strong and powerful. Like the fence of a garden which protects its flowers by warding off intruders like animals, strong wind, etc., the man is seen as the protector and shield for the woman. It is in the context of this interpretation that it makes sense to argue that it is a woman who has no male (company) that one can beat up or assault and walk away with impudence (example 6). Because it is believed that men have the strength and power to protect and defend women, their company is considered crucial to the welfare of the woman. P2Y1 attests to the relevance of this perception even in contemporary society when he notes that his presence at home alone (when he goes home for vacation - he is a Senior High School teacher in a different town), without any action, is enough to ward off students who use a path behind his house to school. He is however informed of how they make noise and sometimes break in for petty thefts in his absence. What is interesting (and this is corroborated by P2Y1) is that not all men live up to these societal expectations of them, but they still enjoy what Connell calls "patriarchal dividend" (2005: 1808; 2002: 26), just for being males. This is what is referred to in the literature as complicit masculinity (Connell 1995).

The power of men, as the protectors of women is made stronger in example (7). Unlike examples (5) and (6) which highlight the weakness or vulnerability of the woman in an attempt to project men's power, example (7) portrays women as powerful, strong, to the extent that she can even buy a gun - a weapon for war, which is considered stereotypically masculine. However, even in cases where she has attained/acquired a 
stereotypically masculine status, she is still considered to be under the care, protection and direction of the man. Whoever she is and whatever she has are under the man's care and authority. This emphasises the point that men are indispensable in the lives of women. The examples discussed in this section thus largely reflect the hegemonic inclinations of the Akan/Ghanaian society, as they portray the power of men over women.

\subsection{Men as providers}

Another major ideal of masculinity in Ghana/Africa, and for many cultures, is the concept of the male breadwinner (see Willott and Griffin 1996, Lindsay 1999, 2007, Obeng 2003, Adomako Ampofo and Boateng 2011, Adinkra 2012, Diabah and Amfo 2015, Diabah forthcoming). Miescher places it under the concept of "adult masculinity" among the Akan of Ghana (2005:75). As a mark of being a man, indicating the transition from boyhood to manhood, a real man is expected to be able to take care of his family, and Ghanaian men strive hard to fulfil this expectation. A man who fails to fulfil this socio-cultural expectation is often perceived as not man enough. This concept of the male breadwinner is reproduced and reinforced in a number of the proverbs, as exemplified in (8) to (10) below.

\section{Jbaa ho ye fe a, na efiri sbarima.}

'If a woman is beautiful, it is because of a man'

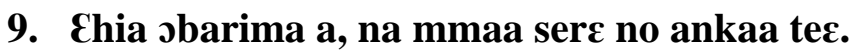

'It is when a man is poor that women ask (beg) him to pluck oranges for them'

\section{Sika ne barima}

'Money is man'

In example (8), men's breadwinning competencies are shown in how they are praised for their female partners' beauty. As Diabah and Amfo (2015) explain, because women in the past were mostly absorbed in domestic activities, they became dependent on men, who were seen as the providers for the family, for their material needs. It is therefore not surprising that men took (and still take) credit for their wives' beauty and achievements. This is regardless of the fact that most women now take care of part or all of their own needs, and sometimes those of their husbands and other family members. For instance, our focus group participants (Year 1 group) recounted various experiences of how their wives "rescued" them from embarrassment. These include secretly putting money in his wallet at a restaurant when she realised the man had no money to pay for the food (P1Y1); giving money to him in the bedroom so he could give it to the children as their daily allowance (P3Y1); giving him her bank card so he could provide house-keeping money (P3Y1) and pay children's school fees (P4Y1); 
giving him money so he could get Christmas gifts for the lady's parents (P5Y1). Here, even when women make the financial provisions, their husbands take the credit in order to satisfy societal expectations of them as "real" men. Since it is normal, and expected, for women to depend on men in the Ghanaian society, and not vice versa, they interpret their wives' acts as virtues meant to portray them (men) positively in the eyes of the society. They see this as a struggle to fulfil societal expectations of them as "real men". Discussions from the two focus groups therefore highlight the frustrations men go through when they are unemployed or have challenges for which they are unable to provide for the family. It is this kind of condition that will make women turn men who cannot provide for the family into their puppets, as suggested by example (9). In other words, a man who has no money and thus cannot provide for the family can be instructed by women to do any menial jobs. This is particularly important since example (10) makes us understand that money is what makes a man. The following comments from P1Y2 and P2Y2 illustrate these further:

P1Y2: ... a man who refuses to work hard or stays at one place to the extent that he lives like a poor man; for them, any odd job could be given to you ... all odd jobs will be reserved for you because you are not successful.

P2Y2: ... if you are supposed to be the breadwinner for the house and it comes out that you don't have a job, you are not able to provide for the house ... so you too they will make you do the house chores ... but for a man who is resourceful, you won't even get him at home to give him any useless things to do.

They see this "compulsory" breadwinner role as a "burden of masculinity", since failure to live up to expectation portrays them as not men enough (Ratele 2008: 529). They believe that the same women who may have been benefitting from them when they had money would be the same to "mock at" them or use them for "useless" jobs (P2Y2). These accounts are consistent with findings from Ghana and other parts of Africa (see Adomako Ampofo and Boateng 2011, Ratele 2008). In their study of multiple meanings of manhood among boys in Ghana, Adomako Ampofo and Boateng, for example, note how the principle of the male breadwinner has created a situation in which "men feel compelled to 'provide' for their families and experience their masculinity as threatened if they are unable to fulfil this role" (2011: 47). Ratele (2008) also argues that working and producing income to support the family are key prerequisites for being a man in many cultures. The opportunities for African men to fulfil this "burden" of masculinity are limited because of the high unemployment rate and the fact that salaries for many people are below poverty lines. This, he hypothesises, can be linked to "levels of both instrumental and expressive male violence" (2008:529, see Prinsloo 2007, Schönteich \& Louw 2001). The interpretation being that, fulfilling breadwinning competencies 
satisfies ego needs as it portrays males as being real men, and failure to satisfy this ego need can find expression in violence or retreating into passivity.

\subsection{Men as action- or results-oriented}

Another representation of men in the dataset is perceiving them as action-oriented. The following examples illustrate this representation.

\section{Dbarima beko a, عwつ ne tirim.}

'If a man is going to fight, it is in his head'

12. Dbarima gyae adwooguo a, ne nan po.

'If a man withdraws from an uncompleted venture, his legs become shaky'

Seeing men as action-oriented is aptly captured in example (11). What makes a man is not a lot of talk about what he can do, or what he is about to do; rather, it is about getting it done. Like the Akan maxim ahwenepa nkasa (a precious bead does not rattle, i.e. it does not need to rattle and draw attention to itself because we already know its value), we place value on the actions rather than on mere talk - action speaks louder than words. In other words, you are not brave merely because you say you are. This representation is in contrast to the stereotypical representation of women as chatterboxes or as frivolous in their use of language (see, for example, Lakoff's seminal work on language and women's place, 1975).

In example (12), the emphasis on what makes a man is on getting his task completed with results, and not just getting it started. This view is not exclusive to the Akan or Ghanaian culture. Among the Baganda of Uganda, the boy is referred to as Naatuukirira, which translates as "I will persevere to the end". On the contrary, the girl is called Gannemeredde "I cannot go any further", (Kiyimba 2010). Thus, not much perseverance is expected of the female while the male is not expected to give up in the middle of a task, no matter how daunting.

\subsection{Men as lecherous}

Another important masculine ideal in Ghana is phallic competence or sexual prowess (Diabah 2015, Fiaveh, Izugbara, Okyerefo, Reysoo and Fayorsey 2015, Adomako Ampofo et al 2009). A man is not considered a man if he is sexually weak (Diabah 2015). Sexual potency and competence may sometimes be judged by the number of wives or partners a man has, the number of children he has and his desire for sex; hence the stereotypical representation of men as lecherous. A man who does not show any 
interest in sex is often branded as impotent, afraid of women and, thus, less of a man. Examples (13) and (14) show the Akan construction of men and their sexual desires:

\section{Obarima se sbepere $\varepsilon t w \varepsilon$ ho a, ma ompere: na na ho ba a, na sbehunu se etwe nye aduane.}

'If a man says he will struggle over vagina too much, let him; but when he has "come" (ejaculated), then he will know that vagina is not food'

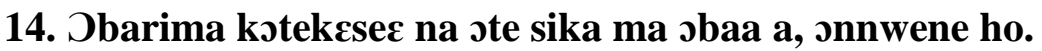

'If a man with a big penis gives money to a woman, he doesn't think about it'

Both examples (13) and (14) represent men in ways that suggest that they have insatiable desires for sex. In (13), this is highlighted in the sentence sbepere ctwe ho "he will struggle over vagina", i.e. mistaking his strong desire for a necessity in life (food). Thus, men desire sex as if it is food, lack of which may kill them. However, they realise after ejaculation that it is no big deal. It is this same unquenchable desire that will make a man with a big penis, for fear of a possible rejection because of the size of his penis, willing to give out any amount of money to a woman so long as she is ready to "receive him" and satisfy his sexual desires (example 14). Although this perception (that women are afraid of a bigger penis) may be true for a section of the Ghanaian public (possibly those with small vaginas), it is inconsistent with studies that suggest that "there is the belief that the larger a male's penis the more pleasure a woman derives from sex, depending on the size of her vagina" (Fiaveh, Okyerefo, and Fayorsey 2015: 699, cf. Carroll 2007). Fiaveh, Izugbara, Okyerefo, Reysoo and Fayorsey (2015) and Fiaveh, Okyerefo and Fayorsey's (2015) findings show that what women do not like is a small penis since it "cannot stimulate their sexual pleasure satisfactorily and could not perform certain sexual positions" (Fiaveh, Okyerefo and Fayorsey2015: 708); but the most preferred is 'an average size penis' (p.708). The essential point here, however, is that the man is ready to pay whatever price is required for sexual gratification.

\subsection{Consequences of polygamy}

A possible offshoot of representing men as lecherous could be polygamy. A man with a strong sexual urge is likely to have multiple sexual partners. Although polygamy is no longer a very popular practice in Ghana, marriages contracted under the Customary Law are potentially polygamous (Awusabo-Asare 1990), and the society seems to be more tolerant of men with multiple sexual partners, whether this has been formalised through marriage or not. Men in polygamous marriages may have the "benefit" of 
having many sexual encounters; but polygamy also has consequences, as noted in the examples (15) and (16) below.

\section{Mmaa dodos kunu ntoma ye fi a, ono ara na osie.}

'If the husband of many women has a dirty cloth, he himself washes it.'

\section{Mmaa dodos kunu wu a, cksm na aku no.}

'If the husband of many women dies, then it is hunger that killed him.'

As noted in Appiah et al.'s (2007) commentary on example (15), it is expected that a man will use his own cloth to cover the woman who comes to his house (as was the tradition) to sleep with him. In a polygamous marriage, none of them will want to wash the cloth which has been used to cover the others. He is therefore forced to wash them himself. Similarly, example (16) indicates how a man in a polygamous marriage can die of hunger because each woman will expect the other person to cook for him. Thus, even though the Ghanaian society is tolerant of "polygamous" men, they are enlightened about the consequences of their actions through such proverbs. Some focus group participants (Moslems) also note that although polygamy is sanctioned on religious grounds, contemporary realities (e.g. high unemployment rates which may hinder men's ability to provide for a large family) make it unattractive.

\subsection{The superiority of men}

One of the major tenets of the concept of hegemonic masculinity is legitimising "the dominant position of men and the subordination of women" (Schippers 2007: 94, see section 4 for a discussion). As people living in a patriarchal society, it is not surprising that a number of the Akan proverbs (6, second to representing men as brave, 17) allude to the dominant position or superiority of men. We discuss three of such examples here.

\section{Obaa na sda sbarima akyi}

'A woman lies behind the man.'

18. Mmarima nni fie a, mmaabasia yi won ho kyere.

'When men are not present, then women expose themselves.'

19. Mmarima mu nni sketewa.

'Among males there is no inferior/smaller one.'

The examples in this section aptly capture the Akan's hegemonic inclination. Example (17) notes the second place of women while emphasising the headship and leadership 
position of men. In example (18), men and their activities take precedence over women's. It is only in their absence that women have the chance to show their potential. Example (19) also attests to male supremacy. Since there is no inferior male (example 19), it may be argued that a younger male is likely to be considered superior to an adult female. This may be supported by the Akan/Ghanaian practice of ammaneebs "missiontelling" where it is the male among a group who is requested to inform their host why they are there. Even in cases where the male is the youngest or does not have the requisite skill, the woman who tells the mission must indicate that she is doing it on his behalf. This tradition is still practised in spite of the fact that research has shown that age (seniority) supersedes or blurs the lines of gender in Africa (Akyeampong and Obeng 1995, Oyewumi 1997, Miescher 2007). Supporting the view of seniority in favour of males in Africa, Kiyimba (2010) suggests that "African oral literature both originates and consolidates stereotypes of male superiority."

Focus group participants agree that although perceptions about male dominance still persist in contemporary Ghanaian society (especially in rural Ghana and among the non-educated), many men hardly insist on their traditional "rights" because of global gender awareness and women empowerment. They also cite examples of the strides women have made in Ghana's economy and politics (e.g. Chief Justices Georgina Theodora Wood and Sophia Akuffo) to support their argument that women are not treated as 'second class citizens' (P5Y1).

\subsection{Marginalised and subordinate masculinities}

Because masculinities are multiple and diverse, some are dominant, highlighted and celebrated (e.g. men as brave, protectors, providers); but others are marginalised and relegated to the background. We use marginalised and subordinate masculinities in this study to mean any form of masculinity that the Akan society disregards or looks down upon. In the sense of marginalised masculinity, this refers to men who are looked down upon based on their disability. And in the sense of subordinate masculinity, this refers to men who exhibit qualities considered as opposite to those valued in hegemonic masculinity (cf. Edley and Wetherell 1995, Wetherell and Edley 1999, Connell 2005, 1995). Examples of these groups are shown in the examples below:

\section{Obarima a odi mmaafodie na ssoa bokiti.}

'A man who follows women too much carries a bucket'

21. Ehia sbarima a na mmaa sere no ankaa tee.

'It is when a man is poor that women ask (beg) him to pluck oranges for them' 


\section{Mmarima nni kurom a, na akyakya tu mirika kyere mmaa}

'If there is no (real) man in town, the hunchback runs to show off before women'

Examples (20) to (22) represent different kinds of men who fall short of the hegemonic standards discussed above. Carrying buckets or pots to go and fetch water from the stream (to be used for cooking, cleaning etc.) is a traditionally feminine practice in Ghana. A male who is fond of being in the company of women will become their puppet, and he can be used for doing things considered as feminine (example 20). Society looks down upon such men and does not consider them real men since it is believed that they are controlled by women (instead of the reverse) and do not have a mind of their own. This is similar to example (21), in which the man is controlled by women because of poverty. As discussed extensively in section 6.3, poverty (the fact that the man can no longer fulfil his breadwinner role, and a woman may probably be taking care of him) disempowers men and makes them "available" for women to use them for "any useless things" (P2Y2). Responses from our FGDs show that although it is becoming a norm that women contribute financially to the upkeep of the home in contemporary society, a man who brings no money home loses "his voice" and power as the head of the family when it comes to taking decisions on issues that require money to resolve. The idea of marginalised masculinities and their (implicit) comparison to women in these examples reinforces the subordinate role of women.

In example (22), on the other hand, some men are marginalised and are not considered as real men on the basis of their disability. Respondents from our focus groups note that perceiving disability as inability, and seeing such men as less of men, does not hold much water in contemporary society because of the education people have received on such issues; although some sections of the public (especially in rural Ghana) still look down on some of these people on religious and other cultural grounds. They however note that there are limitations on what such people can do, depending on the kind and the level of disability. This is particularly true in developing countries like Ghana where we lack the needed resources to help them realise their full potential as (Ghanaian or African) men.

\section{Traditional values vs. Contemporary demands - Keeping the balance}

As reflected in the proverbs, and reiterated by the FGDs, traditionally, gender roles are defined. It can be seen from section 6 that men are expected to show unrestrained bravery, protect and provide for their families, show leadership and be determined and action-oriented. In addition, society does not frown on their huge sexual appetite which 
often results in having multiple sexual partners, whether it happens in a formalised polygamous setting or not.

Participants of our FDGs endorsed the view that the proverbs encourage and motivate men to perform their expected roles, and that they do reflect, to a large extent, what happens in contemporary societies. There was the recognition that increasingly, women are being empowered to take up roles which are the traditional preserves of men. They recognised the need for shared responsibilities, but they suggest that there is the need to be mindful of the limits, for fear of men losing their superiority and generally privileged positions in the Ghanaian society. Indeed, there was the suggestion that creating opportunities for women, tend to reduce the opportunities for men to perform their roles adequately. Some men feel threatened by the numerous opportunities women get access to these days. When a woman is empowered to take responsibility for herself, she may not need a man to protect her (5) or provide for her needs (8), and this can lead to usurping their traditional powers (P6Y1). Thus, even though men are ready to accept the support provided by women, they are mindful of still keeping their superior status. P1Y2 for instance argues that although he welcomes his wife's support and he does not mind doing certain things considered as feminine because of his education and enlightenment, "when the women want to make the equality argument, then there is a problem."

\section{Conclusion}

Both the recurring themes from the proverbs and responses from our FGDs point to clearly demarcated gender roles and norms among the Akans of Ghana. The implication of such demarcation is that it tends to put undue pressure on men (and women), as they struggle to fulfil societal expectations of them as real Ghanaian or African men. Contemporary realities (e.g. economic hardships, women empowerment, global gender awareness) have however blurred the lines of these gender demarcations in many areas, but some men still hold very entrenched positions. As they welcome women's financial (and other) contributions to the family, for example, they warn that this should not be taken as a licence for 'demanding' power-sharing. Even though the contemporary Ghanaian man, in many instances, welcomes the woman's contribution in areas where men are expected to provide and perform, they still would like to enjoy the full dividends of their masculine status, and are therefore willing to take credit for things which have been done on their behalf by the women they are associated with. Such views point to the fact that patriarchal societies like Ghana are conscious about maintaining the status quo when it comes to the leadership roles expected of men and its almost invariable consequence of female subjugation in our communities. 


\section{References}

Adinkrah, Mensah. 2012. "Better Dead Than Dishonoured: Masculinity and Male Suicidal Behaviour in Contemporary Ghana." Social Science \& Medicine 74: 474-81.

Adjei, Stephen Baffour. 2016. "Masculinity and Spousal Violence: Discursive Accounts of Husbands Who Abuse Their Wives in Ghana." J Fam Viol 31:41122

Adomako Ampofo, Akosua and John Boateng. 2011. "Multiple meanings of manhood among boys in Ghana." In African Sexualities: A Reader, edited by S. Tamale, 38-62. Cape Town: Pambazuka Press.

Adomako Ampofo, Akosua, Michael P. K. Okyerefo and Michael Pervarah. 2009. "Phallic competence: Fatherhood and the making of men in Ghana." Culture, Society and Masculinities 1: 59-78.

Akyeampong, Emmanuel and Pashington Obeng. 1995. "Spirituality, Gender, and Power in Asante History." International Journal of African Historical Studies 28(3): 481-508.

Amoah, Elisabeth. 1991. "Femaleness: Akan concepts and practices." In Women, religion and sexuality, Studies on the impact of religious teachings on women, edited by J. Becher, 129-153. Philadelphia: Trinity Press Int.

Appiah Peggy, Anthony K. Appiah, and Ivor Agyeman-Duah (2007) Bu me be: Proverbs of the Akans. Oxford: Ayebia Clarke.

Asante, Emmanuel K. A. (2002). Akan proverbs: Their origins, meanings and symbolic representations in Ghanaian material cultural heritage. Accra: Asempa Publishers.

Bibiebome, Eric Ziem. 2010. Language shift and maintenance among Gas in Accra (Unpublished Masters thesis), University of Ghana, Accra.

Connell, R. Raewyn, and James W. Messerschmidt. 2005. "Hegemonic Masculinity: Rethinking the Concept." Gender \& Society 19 (6): 829-59.

Connell, W. Raewyn. 2005. Masculinities. Berkeley: University of California Press.

Diabah, Grace. 2018. "The Modern Man in Ghanaian Radio Adverts: A Reproduction of or a Challenge to Traditional Gender Practices?" In Feminist Perspectives on Advertising: What's the Big Idea? edited by K. Golombisky, 217-38. Lexington Books.

Diabah, Grace. 2016. "SEX-FOR-GENDER metonymy? A consideration of three expressions from Akan." Gender and Language 10: 170-90. 
Diabah, Grace. 2015. "From 'Recharger' to 'Gidi-power': The representation of male sexual power in Ghanaian radio commercials." Critical Discourse Studies, 121.

Diabah, Grace and Nana Aba Appiah Amfo. 2015. "Caring supporters or daring usurpers? The representation of women in Akan proverbs." Discourse \& Society 26: 3-28.

Durkheim, Emile. (1933). Division of labour in society. Illinois: The Free Press of Glencoe.

Edley, Nigel, and Margaret. Wetherell. 1996. "Masculinity, power and identity." In Understanding Masculinities, edited by M. Mac an Ghail, 97-113. Buckingham: Open University Press.

Essegbey, James. 2009. "On assessing the ethnolinguistic vitality of Ga in Accra". In The languages of urban Africa, edited by F. McLaughlin, 115-10. London: Continuum International Publishing Group.

Fiaveh, Daniel Y., Chimaraoke O. Izugbara, Michael P.K. Okyerefo, Fenneke Reysoo and Clara K. Fayorsey. 2015. "Constructions of masculinity and femininity and sexual risk negotiation practices among women in urban Ghana." Culture, Health \& Sexuality 17: 650-62.

Fiaveh, Daniel Y., Michael P.K. Okyerefo, and Clara K. Fayorsey. 2015. "Women's Experiences of Sexual Pleasure in Ghana." Sexuality \& Culture 19: 697-714.

Ghana Statistical Service. 2012. 2010 Population and Housing Census: Summary Report of Final Results. Accra: GSS.

Guerini, Federica. 2008. Multilingualism and language attitudes in Ghana: a preliminary survey. Ethnorêma, Anno IV, 4: 1-33. http://www.ethnorema.it. Last accessed on 6 June 2018.

Kalu, Anthonia C. 2010. "Preface". In Masculinities in African Literary and Cultural Texts, edited by H. N. Magambi and A. J. Tuzyline, 1-2. Oxfordshire: Ayebia Clarke Publishing Limited.

Kiyimba, Abasi. 2010. "Men and Power: Masculinities in the foltales and proverbs of the Baganda". In In Masculinities in African Literary and Cultural Texts, edited by H. N. Magambi and A. J. Tuzyline, 35-49. Oxfordshire: Ayebia Clarke Publishing Limited.

Lindsay, Lisa A. 1999. "Domesticity and Difference: Male Breadwinners, Working Women, and Colonial Citizenship in the 1945 Nigerian General Strike." American Historical Review 104: 783-812.

Miescher, Stephan F. 2005. Making Men in Ghana. Bloomington: Indiana University Press. 
Mugambi, Helen N., and Allan J. Tuzyline, eds. 2010. Masculinities in African Literary and Cultural Texts. Oxfordshire: Ayebia Clarke Publishing Limited.

Obeng, Pashington. 2003. "Gendered Nationalism: Forms of Masculinity in Modern Asante." In Men and Masculinities in Modern Africa, edited by L. A. Lindsay and S. F. Miescher, 192-208. Portsmouth, N.H.: Heinemann.

Obeng, Samuel Gyasi. 2005. Akan and Nyo languages. In Encyclopedia of Linguistics, edited by P. Strazny, 28-31. New York: Routledge.

Opoku, Kofi Asare. 1978. West African Traditional Religion. Accra: FEP International Private Limited.

Oyewumi, Oyeronke. 1997. The Invention of Women: Making an African Sense of Western Gender Discourses. Rochester: University of Minnesota Press.

Prinsloo, Megan, ed. 2007. A profile offatal injuries in South Africa: 7th Annual Report of the National Injury Mortality Surveillance System, 2005. Medical Research Council/University of South Africa Crime, Violence and Injury Lead Programme.

Ratele, Kopano. 2008. "Studying Men in Africa Critically." In Masculinities in Contemporary Africa, edited by E. Uchendu, 18-33. Sénégal: Imprimerie Saint-Paul.

Sarpong, Peter. 1977. Girls' Nubility Rites in Ashanti. Tema: Ghana Publishing Corporation.

Schippers, Mimi. 2007. "Recovering the feminine other: masculinity, femininity, and gender hegemony." Theory and Society 36: 85-102.

Schönteich, Martin. and Louw, Antoinette. 2001. "Crime in South Africa: a country and cities profile.” Institute for Security Studies, Occasional Paper No 49.

Simons, Garry. F. and Charlse D. Fennig, eds. 2018. Ethnologue: Languages of the World, Twenty-first edition. Dallas, Texas: SIL International. Online version: http://www.ethnologue.com. Last accessed on 18 June 2018.

Uchendu, Egodi. 2008. "Introduction: Are African Males Men? Sketching African Masculinities?" In Masculinities in Contemporary Africa, edited by E. Uchendu, 18-33. Sénégal: Imprimerie Saint-Paul.

Willott, Sara, and Christine Griffin. 1996. "Men, Masculinity and the Challenge of Long-term Unemployment." In Understanding Masculinities, edited by M. Mac an Ghail, 77-92. Buckingham: Open University Press. 